\title{
The effects of annealing temperature on optical properties of 2, 6-bis (3- (carbazol-9-yl) phenyl) pyridine films'
}

\section{Asim MANTARCI ${ }^{*}$}

\begin{abstract}
In this research, 2, 6-bis (3- (carbazol-9-yl) phenyl) pyridine films were synthesized using spin coating to study changes in its optical properties for different annealing temperatures. The films were annealed at $30,50,70,90,110,120,140$ and $160{ }^{\circ} \mathrm{C}$ degrees in the presence of nitrogen. The material studied is one of the basic materials of the organic light emitting diode and forms the light emitting layer. In the results obtained from the films, for UV ultraviolet region, the highest absorption was obtained at $50{ }^{\circ} \mathrm{C}$ annealing, while the lowest absorption was $160{ }^{\circ} \mathrm{C}$. Optical band gap energies of films range from 3.35 to $3.43 \mathrm{eV}$. Refractive index distributions depending on the annealing temperature of the films were studied in detail. The refractive indices of the films at $440 \mathrm{~nm}$ wavelength varied between 2.71 and 3.39 according to different annealing temperatures. It is observed that it varied between $3.06 \mathrm{eV}$ and $3.19 \mathrm{eV}$. It was observed that in the visible region of the spectrum, refractive index of the films increased in a sharp linear behavior at a wavelength of $350 \mathrm{~nm}$. Annealing took place in two regimes that increase and decrease the effect of the optical band gap energy of the film. It can be seen that the percentage of reflection of all films at the wavelengths after $500 \mathrm{~nm}$ was almost constant. It has been evaluated that the films had $70 \%$ transmittance at $70{ }^{\circ} \mathrm{C}$ (up to $160{ }^{\circ} \mathrm{C}$ ) and after this point, their transmission (\%) was above $70 \%$ and films can be used in the permeability devices of this feature. As a result, the optical properties of films (bandgap energy, absorption band edge energy, refractive index, refractive (\%), and transmission (\%), etc.) were measured and evaluated according to the annealing temperature.
\end{abstract}

Keywords: Optical Properties, Annealing Effects, Organic Light Emitting Diode, Film

\footnotetext{
${ }^{1}$ Asim MANTARCI (Orcid ID: 0000-0001-8369-3559), Muş Alparslan Üniversitesi, Tıbbi Hizmetler ve Teknikler Bölümü, Muş, Türkiye

*Sorumlu Yazar/Corresponding Author: Asim MANTARCI, e-mail: a.mantarci@alparslan.edu.tr
} 


\section{INTRODUCTION}

Organic light emitting diodes (OLED) are important materials for the industry as they are used in various lamps such as solid state light emitting systems, panel illuminators, fluorescent lamps (Skuodis et al., 2017; Liang et al., 2017; Zhao et al., 2016; Mullemwar et al., 2016). Organic light emitting diodes are generally composed of five layers. These; the bottom layer is the substrate layer, then the hole transfer layer, the emissive layer, the electron transfer layer, and finally the cathode layer, respectively. The emissive layer plays a vital role in the production of OLEDs. Luminescent material such as phosphorus is important because it provides high quantum efficiency in OLED devices. 2,6-bis (3- (9H-Carbazol-9yl) phenyl) pyridine has become one of the most famous phosphorescent and bipolar host materials as a light emitting (emissive) layer used in the design of OLED devices. Carbazole electron donors have a feature that combines high triplet energy and a pyridine electron acceptor with high electron attractiveness. Bipolar host material is molecules that can mediate hole and transport injection and contain electron withdrawal. Beyond this; 2,6-bis (3- (9H-Carbazol-9-yl) phenyl) pyridine material can improve hole electron injection for white and blue phosphorescent organic light emitting diode (OLED) (Tsai et al., 2014). Many scientists have researched 2,6-bis (3- (9H-Carbazol-9-yl) phenyl) pyridine to understand the properties of the material, apply the material to the high-tech device and contribute to the literature. A reported study (Koh et al., 2012) investigated that white-organic light emitting diodes (WOLEDs) were produced based on blue fluorescence -OLEDs, which are microstructural color conversion layers containing red and green phosphors. In the emissive layer of the device produced, 2,6bis (3- (9H-Carbazol-9-yl) phenyl) pyridine was used, $8 \%$ and $18 \%$ by weight. They achieved large low-angle spectral variation and color stabilization from the study, but observed that productivity decreased unusually. In this study, the important benefits of the produced white organic light emitting diode, which gives an example of color stability and mechanical flexibility, have been demonstrated. In addition, a versatile and high quality light source was produced, and therefore; this study guided the development of light sources of the new generation WOLEDs (white light emitting diode). In the literature, many researchers have produced many high efficiency and high technology organic light emitting devices using 2,6-bis (3- (9H-Carbazol-9-yl) phenyl) pyridine material (Wu et al., 2017; Guo et al., 2016; Zhao et al., 2016; Chen et al., 2015; Zhou et al., 2016; Yu et al., 2019; Guo et al., 2020; Liu et al., 2020).

This research has two main point of novelty. First, when literature review is done, it is seen that the effect of annealing on the optical properties of 2,6-bis (3- (9H-Carbazol-9-yl) phenyl) pyridine film has not been studied. From this point of view, the effect of annealing effect on the optical properties of this film should be investigated. In this way, the change in the optical properties of annealing can be understood and used in high-tech devices such as WOLED. The other is that the film has not been produced by spin coating method before.

\section{MATERIALS AND METHODS}

The experimental process consists of three steps. The first step is to prepare the material in the form of a solution, and with the help of spin coating, the material is coated on the substrate layer and films are obtained. In the last step, the produced films are exposed to various annealing temperatures and the optical properties of the film are measured.

\section{Obtaining films by spin coating method}

First of all, the material was purchased in the form of powder from Sigma Aldrich. The material was put into tubes by measuring with a precise scale and weighing 0.0132 g. 9 different tubes were 
poured with the same weight of powder material. Then, each tube was dissolved in $3 \mathrm{~mL}$ of Dichloromethane (DCM Dichloromethane) solvent. In order to be homogeneous, tubes shook up should be at least 25 minutes with RS-VA 10 -vortex shaker machine. Subsequently, the obtained material was covered with a coating (Vtc-100 Vacuum Spin Coater) machine by rotating on the substrate (the glass soda lime glass). Spin coating is an important way of producing thin films in the high tech industry. A process where the solution is spread almost homogeneously on a surface using centripetal force. The spin coating can result in a relatively uniform film with a desired thickness. This process is applied as follows. Firstly, the solution deposited on the substrate. And then, it accelerated the wafer final radial velocity. Solution viscosity, wafer radial velocity, some ambient factor can affect the spin coating process. The thickness measurement technique of the films is as follows. Before coating the films, empty glass thicknesses were measured. Afterward, the film thickness covered with a digital micrometer (iGaging Digital Electronic Outside Micrometer) was measured. The thickness of the films was calculated by removing the empty glass thickness from the final thickness. All produced films are of the same thickness and their thickness is approximately 0.1 micrometer

\section{Annealing of films at various temperatures}

The films are annealed in the presence of nitrogen, 30, 50, 70, 90, 110, 120, 140, $160{ }^{\circ} \mathrm{C}$ separately. Optical properties were measured after each annealing, as detailed in the section below. Annealing time was determined as 20 minutes for each film.

\section{Measuring and Calculating the optical properties of films}

The films are annealed in the presence of nitrogen, 30, 50, 70, 90, 110, 120, 140, $160{ }^{\circ} \mathrm{C}$ separately. Optical properties were measured after each annealing and some optical properties were calculated from experimental results using the single oscillator theory and Tauc theory.

\section{RESULTS AND DISCUSSION}

Figure 1 show the photon wavelength graph in response to the absorption value of the 2, 6-bis (3(carbazol-9-yl) phenyl) pyridine film, which was subsequently annealed at various temperatures. The absorption of the film between 400 and $1100 \mathrm{~nm}$ is listed as follows depending on the annealing temperature; room temperature $>30^{\circ} \mathrm{C}>50^{\circ} \mathrm{C}>70{ }^{\circ} \mathrm{C}>90{ }^{\circ} \mathrm{C}>110^{\circ} \mathrm{C}>120^{\circ} \mathrm{C}>140{ }^{\circ} \mathrm{C}>160^{\circ} \mathrm{C}$. In short, in the visible and near infrared spectrum, it is seen that the film has a tendency to decrease with increasing tempering temperature, with the tendency to absorption. In the UV ultraviolet region, the absorption property of the film shows a nonlinear feature. In the UV ultraviolet region, the highest absorption occurs at $50{ }^{\circ} \mathrm{C}$ annealing temperature, while the lowest absorption is achieved at $160{ }^{\circ} \mathrm{C}$ annealing temperature. Since this absorption value changes the optical band gap energy, which is an important physical parameter in opto-electronic devices, the control of this parameter is important for the production of higher quality devices. In the literature research (Wan, 1992); a thin film of polyaniline has two absorption peaks of $950 \mathrm{~nm}$ and $630 \mathrm{~nm}$, which is a point of higher wavelength value than our value. Figure 2 shows the wavelength graph of the film versus \% transmission values at various annealing temperatures. The highest transmittance in the UV ultraviolet spectrum range was achieved at about $55 \%$. This highest transmission value is obtained at annealing temperature of $160{ }^{\circ} \mathrm{C}$. The lowest transmittance for the UV ultraviolet spectrum range was achieved at about $8 \%$. In the visible region of the spectrum, the transmission (\%) has increased considerably for films at all annealing temperature compared to the ultraviolet region. This sharp/steep linear increase in the $\%$ transmittance value occurred at a wavelength of about $350 \mathrm{~nm}$. The highest transmission (\%) of the film in the visible region was in the range of $85-90 \%$, and this value corresponds to annealing at $160{ }^{\circ} \mathrm{C}$. The lowest transmission (\%) in 
the visible region is in the range of $30-35 \%$, which is the value of the film at annealed room temperature. Films produced in the visible region have $70 \%$ transmission at annealed temperatures of $70{ }^{\circ} \mathrm{C}$ and above (up to $160^{\circ} \mathrm{C}$ ) and films with these properties have the properties to be used in permeability devices (Lee 1996 et al.; Kim 2016 et al.). To calculate the absorption band edge energy of the film, it is necessary to take the derivative of the transmission (\%) according to the wavelength and draw. Figure 3 shows this graphic. Absorption band edge energy value according to various annealing temperatures was calculated by using the formula $\mathrm{E}_{\mathrm{b}-\mathrm{e}}=1240 / \lambda_{\max }$ and the maximum wavelength value was obtained from Figure 3. Table 1 gives the absorption band edge energies of the film at various annealing temperatures. The increasing tendency of annealing regimes of the optical band gap energies of the films are as follows; room temperature- $30{ }^{\circ} \mathrm{C}, 50{ }^{\circ} \mathrm{C}-70{ }^{\circ} \mathrm{C}, 90{ }^{\circ} \mathrm{C}-110^{\circ} \mathrm{C}$ and $140{ }^{\circ} \mathrm{C}-160{ }^{\circ} \mathrm{C}$ in the annealing temperature range. On the other hand, the annealing regimes of the films with a decreasing tendency of optical band gap energies can be listed as follows; in annealing ranges of $110^{\circ} \mathrm{C}-120^{\circ} \mathrm{C}$ and $120^{\circ} \mathrm{C}-140{ }^{\circ} \mathrm{C}$. In the annealing regime of $70{ }^{\circ} \mathrm{C}$ to $90{ }^{\circ} \mathrm{C}$ of the films, the optical band gap energy does not change. Figure 4 is a graph of $(\alpha h v)^{2}$ versus photon energy plots of films annealed at different temperatures. If the wellknown Tauc theorem $\left((\alpha h v)^{\mathrm{n}}=\mathrm{C}\right.$. $\left(\mathrm{h} v-\mathrm{E}_{\mathrm{g}}\right)$ is applied to this graph and by selecting $\mathrm{n}=1 / 2$ in this equation and making a linear fit, the value that cuts 0 in the y axis is the allowed-direct optical band gap energy. Control of these allowed-direct optical band gap energy values is extremely important in the development of optical devices such as WOLED (white light organic light emitting diode) . These values are given in Table 1. Allowed-direct optical band energy is increased by increasing the annealing from room temperature up to $70{ }^{\circ} \mathrm{C}$ annealing temperature. On the other hand, increasing the annealing temperature from $70^{\circ} \mathrm{C}$ to $160^{\circ} \mathrm{C}$ decreases the optical band gap energy values of the film, where it is in 2 regimes to increase and decrease the effect of the film on the optical band gap energy. While the highest optical band gap energy was obtained as $3.50 \mathrm{eV}$ from the films, the lowest optical band gap energy was obtained as $3.35 \mathrm{eV}$. Our optical bang gap values are lower than the literature study (Cheah et al., 2020) of $\mathrm{Ga}_{2} \mathrm{O}_{3}$ thin film produced by sol-gel methgod. Figure 5 shows the \% reflectancewavelength graph for annealing at various temperatures. As seen in the figure, room temperature, $30{ }^{\circ} \mathrm{C}$, $50{ }^{\circ} \mathrm{C}$ and $70{ }^{\circ} \mathrm{C}$ annealing regime, the reflectance value increases sharply at $350 \mathrm{~nm}$ wavelength. The reflectance of the film in $70{ }^{\circ} \mathrm{C}$ annealing temperature increased sharply from $5 \%$ to about $10 \%$. At room temperature, $30^{\circ} \mathrm{C}, 50^{\circ} \mathrm{C}$ annealing temperature, the reflectance value of the film increased sharply from $5 \%$ to about $20 \%$. The reflectance values of all films remained almost constant after $500 \mathrm{~nm}$ wavelength. While the highest reflectance value in the visible region of the spectrum was obtained in 30 ${ }^{\circ} \mathrm{C}$ annealed film; in the same region, the lowest reflectance value was obtained in the annealed film at $160{ }^{\circ} \mathrm{C}$. As a general trend, the increasing annealing temperature decreases the film's reflectance value. This is an indication that annealing process plays a role in modifying the film's reflectance properties. Reflectance property of gold nanorattles impregnated chitosan film was researched in literature (Keshav et al., 2020) and shows similar behavior of our material after $500 \mathrm{~nm}$ wavelength. Figure 6 shows the graphic that gives the refractive index distribution of the film for different annealing temperatures. The refractive index values of the films vary between approximately 1.2 and 3.5 according to the changing wavelength and annealing temperature. It has been observed that the refractive indices of the films increase from about 1.7 or 2 to about 3.2 in sharp linearly in the films at about $350 \mathrm{~nm}$, at room temperature, $30{ }^{\circ} \mathrm{C}, 50{ }^{\circ} \mathrm{C}$ and $70{ }^{\circ} \mathrm{C}$ annealing temperature. In films with $90{ }^{\circ} \mathrm{C}, 110{ }^{\circ} \mathrm{C}, 120^{\circ} \mathrm{C}, 140{ }^{\circ} \mathrm{C}$ annealing temperatures, the refractive index distribution first increases at $350 \mathrm{~nm}$, and then decreases with the increase in varying wavelength. On the other hand, in films annealed at $30^{\circ} \mathrm{C}, 50{ }^{\circ} \mathrm{C}$ and $70{ }^{\circ} \mathrm{C}$, the refractive index values is increasing up to $400 \mathrm{~nm}$ wavelength and beyond this wavelength value, it 
is following an almost unchanged course. Table 1 shows the refractive index values (at $440 \mathrm{~nm}$ wavelength) of films depending on the various annealing temperatures. As can be clearly seen in Table 1, the highest refractive index at $440 \mathrm{~nm}$ wavelength is 3.46 , which was obtained from the annealed film at $30{ }^{\circ} \mathrm{C}$. The smallest refractive index value was obtained as 2.45 and obtained from annealed film at $120^{\circ} \mathrm{C}$.

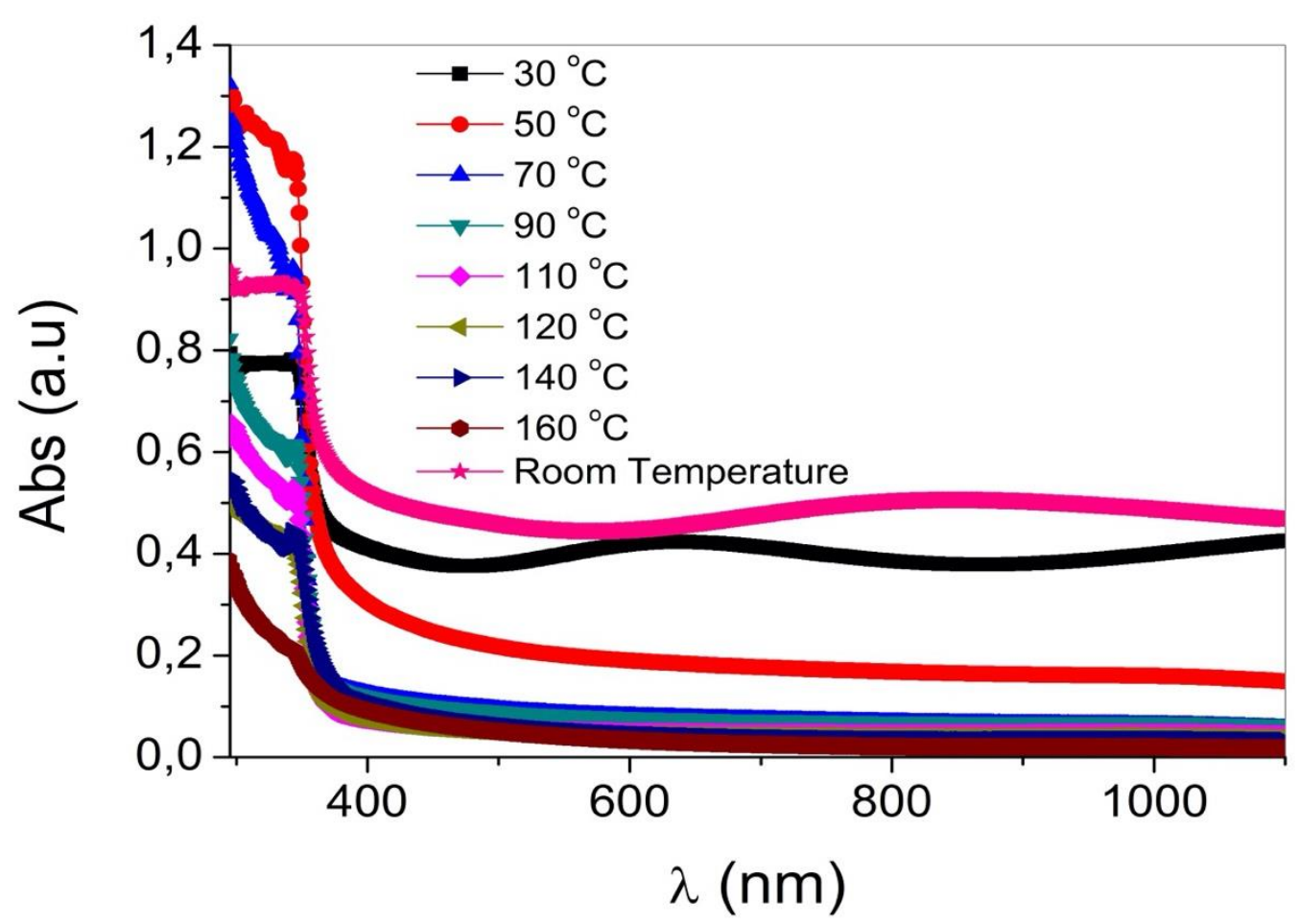

Figure.1. Absorption spectrum of films at various annealing temperatures

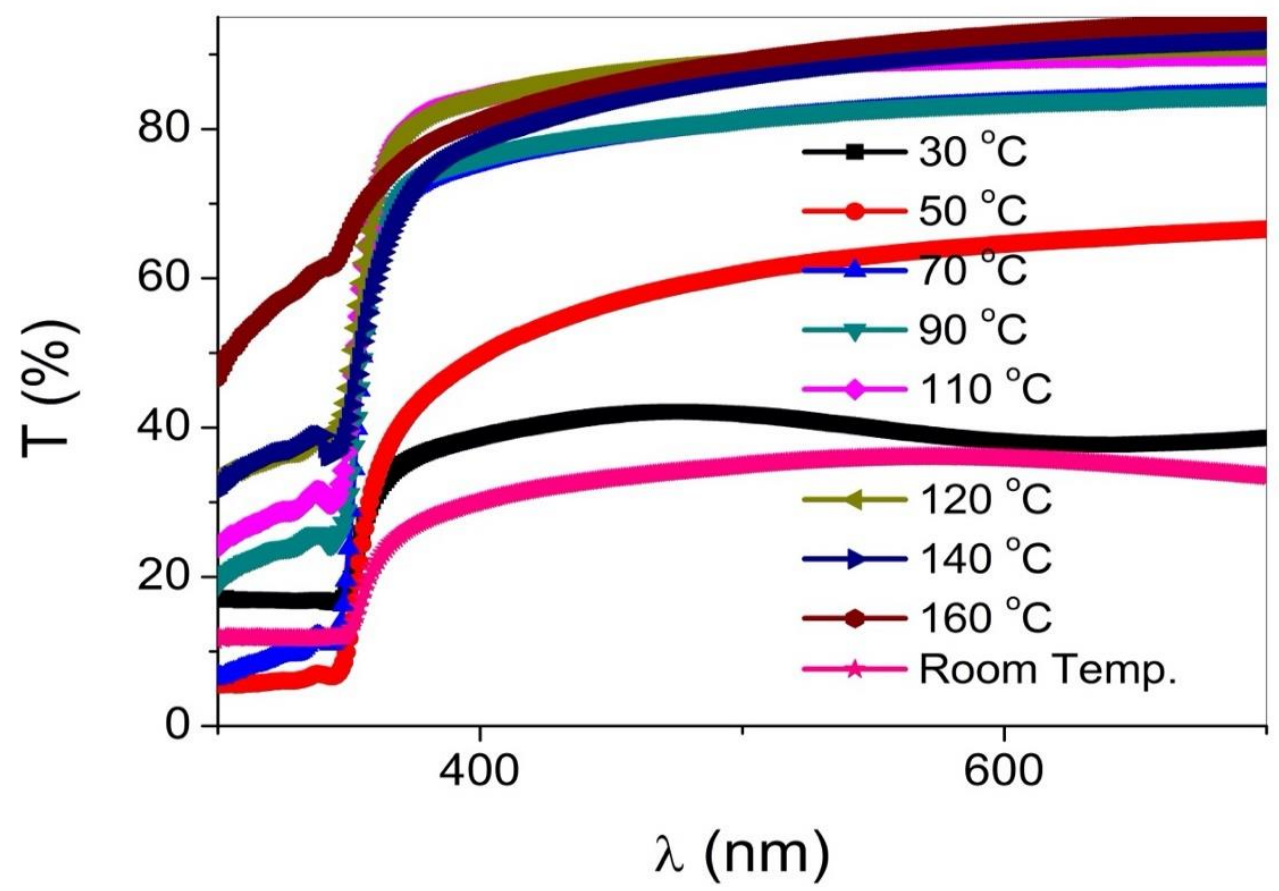

Figure.2. Dependence of films' transmittance values to annealing temperatures 


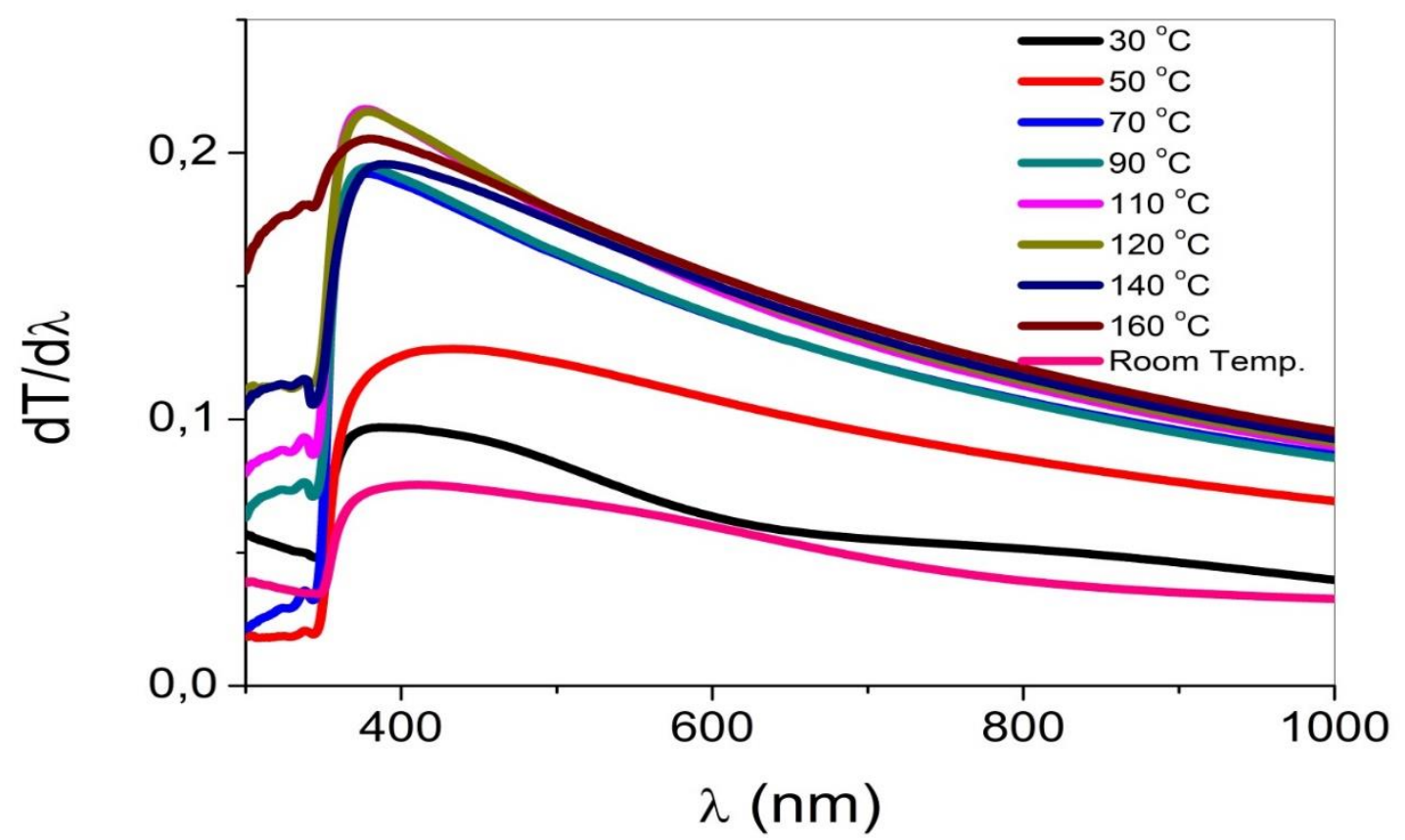

Figure.3. Derivation of transmission spectrum for different annealing temperatures

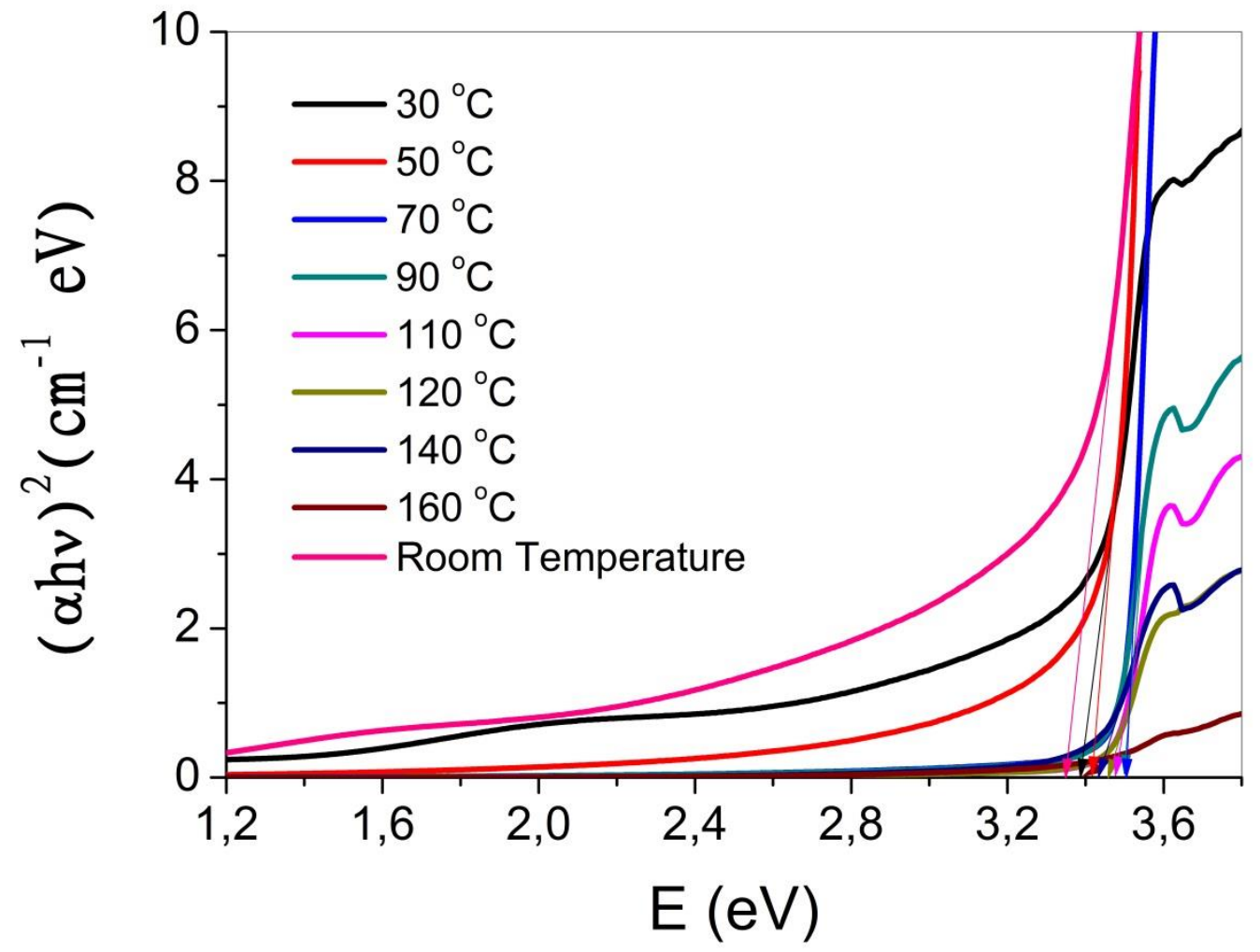

Figure.4. $(\alpha h v)^{2}$ versus photon energy graph of films 


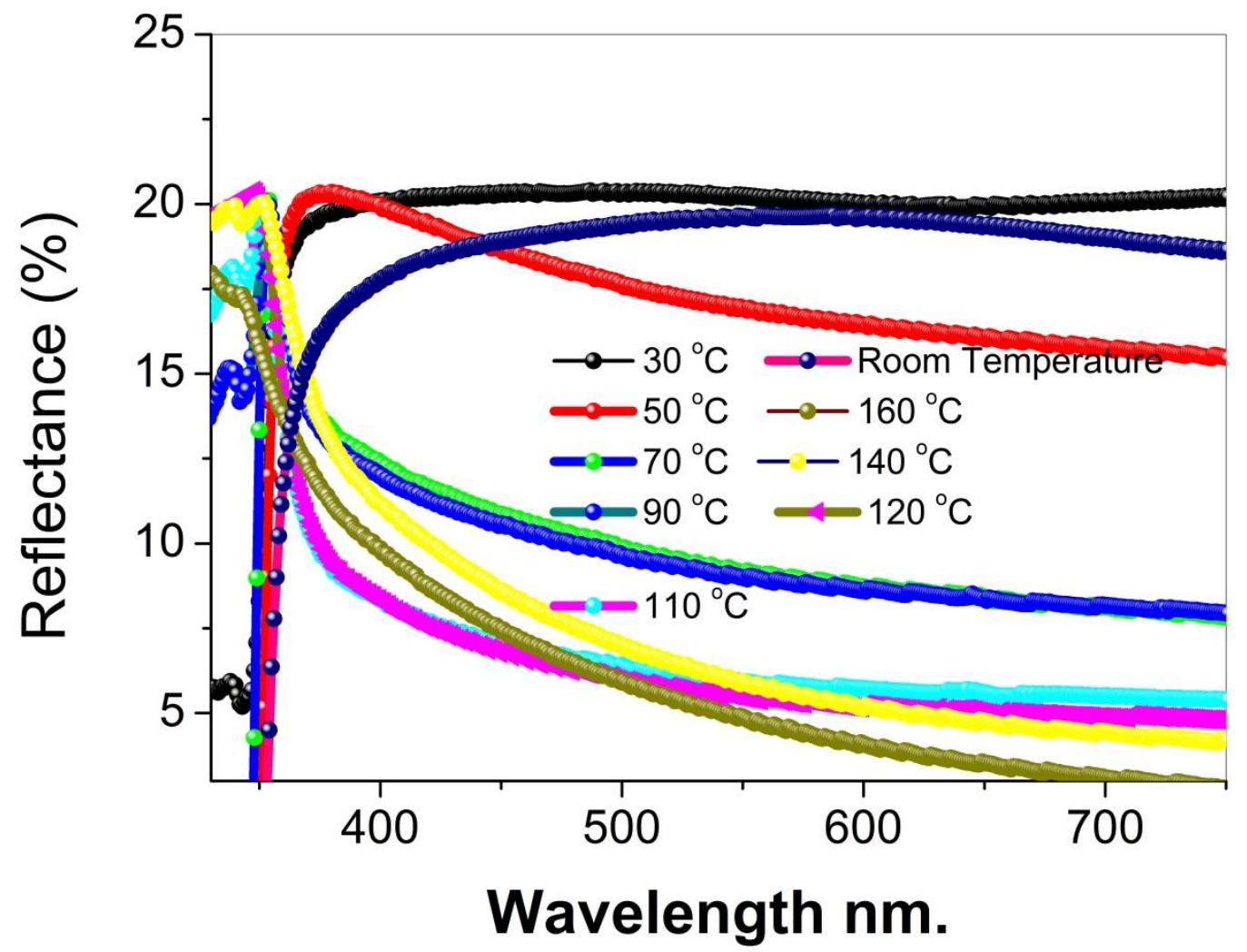

Figure.5. Dependence of reflectance properties of films on annealing temperatures.

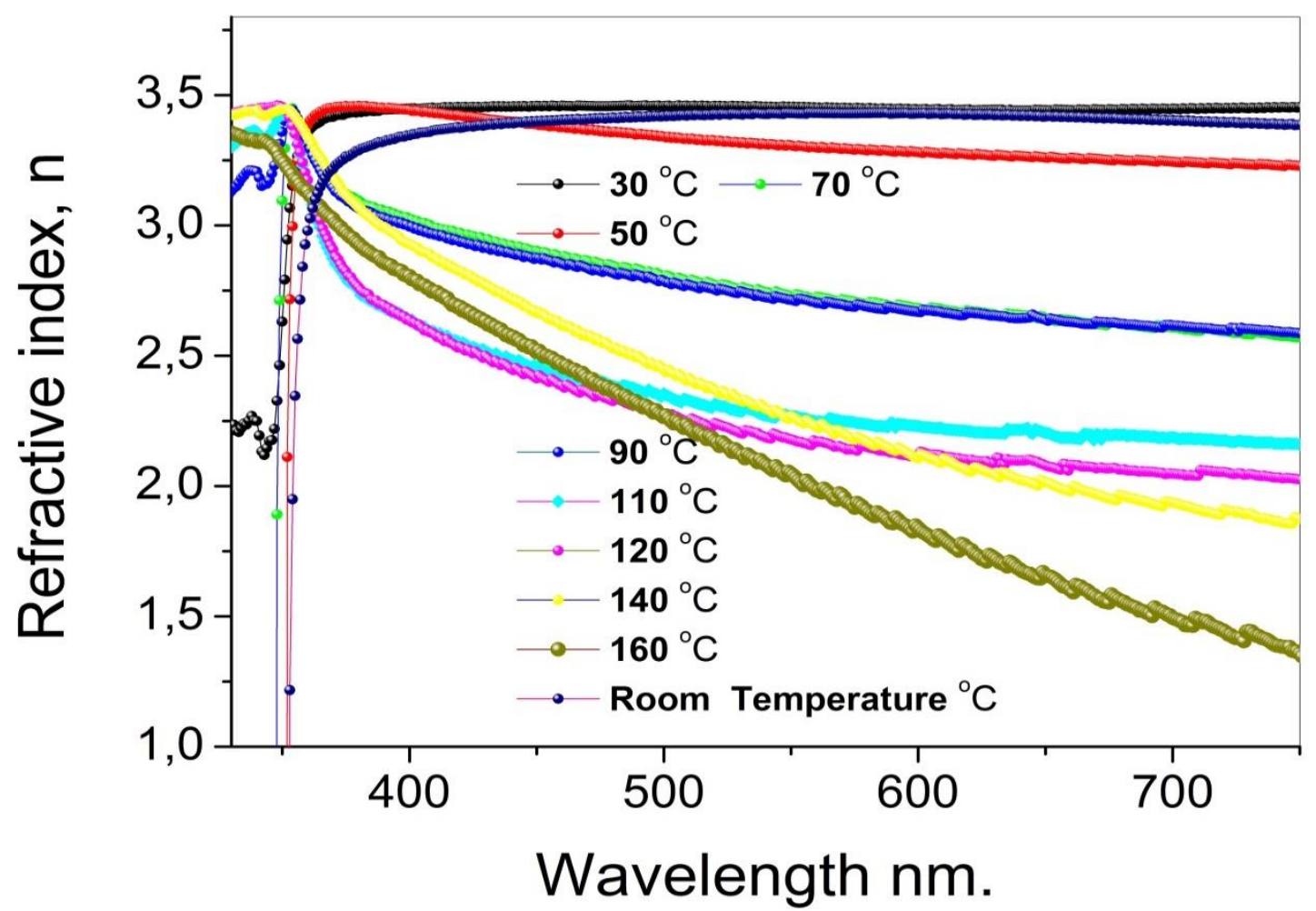

Figure.6. Distribution of refractive index values of films annealed at different temperatures 
Table 1: Important optical properties of films for various annealed temperatures

\begin{tabular}{cccc}
\hline $\begin{array}{c}\text { Annealed temperature } \\
\left({ }^{\circ} \mathbf{C}\right)\end{array}$ & $\begin{array}{c}\text { Absorption band edge } \\
\text { energy }(\mathbf{e V})\end{array}$ & $\begin{array}{c}\text { Optical band gap } \\
\text { energy }(\mathbf{e V})\end{array}$ & $\begin{array}{c}\text { Refractive index value } \\
(\mathbf{a t} \mathbf{4 4 0} \mathbf{~ n m})\end{array}$ \\
\hline $\mathbf{0 d a}$ sicaklığı & 3.06 & 3.35 & 3.39 \\
$\mathbf{3 0}$ & 3.21 & 3.39 & 3.46 \\
$\mathbf{5 0}$ & 2.87 & 3.42 & 3.41 \\
$\mathbf{7 0}$ & 3.27 & 3.50 & 2.93 \\
$\mathbf{9 0}$ & 3.27 & 3.50 & 2.88 \\
$\mathbf{1 1 0}$ & 3.31 & 3.48 & 2.49 \\
$\mathbf{1 2 0}$ & 3.28 & 3.46 & 2.45 \\
$\mathbf{1 4 0}$ & 3.19 & 3.43 & 2.71 \\
\hline
\end{tabular}

\section{CONCLUSION}

By applying various annealing temperatures of the synthesized 2, 6-bis (3- (carbazol-9-yl) phenyl) pyridine film using spin coating, the effects of these temperatures on the optical properties of the film were studied in detail. The use of films in an OLED device, which is an optical device, and thus improving its optical properties, plays a role in the development of high efficiency devices in device applications. The highest absorption in the UV ultraviolet region was obtained at $50{ }^{\circ} \mathrm{C}$ annealing temperature, while the lowest absorption was obtained at $160{ }^{\circ} \mathrm{C}$ annealing temperature. The highest transmittance in the UV ultraviolet spectrum range was achieved at about $55 \%$. This highest transmittance value was obtained at annealing temperature of $160{ }^{\circ} \mathrm{C}$. In the visible region of the spectrum, the transmittance has increased considerably for films at all annealing temperature compared to the ultraviolet region. This sharp/steep linear increase in the $\%$ transmittance value occurred at a wavelength of about $350 \mathrm{~nm}$. Films produced in the visible region have a transparency of over $70 \%$ at annealing temperatures from $70{ }^{\circ} \mathrm{C}$ up to $160{ }^{\circ} \mathrm{C}$. The effect of annealing on the optical band gap energy of the film is in 2 regimes as an increasing (at annealing regime from room temperature to $70{ }^{\circ} \mathrm{C}$ ) and a decreasing (at annealing regime from $70{ }^{\circ} \mathrm{C}$ to $140{ }^{\circ} \mathrm{C}$ ). While the highest optical band gap energy was obtained as $3.50 \mathrm{eV}$ from the films, the lowest optical band gap energy was obtained as $3.35 \mathrm{eV}$. The refractive index values of the films vary between approximately 1.2 and 3.5 according to the changing wavelength. It is inferred that the refractive indexes of the films increase from about 1.7 or 2 to about 3.2 in sharp linearly in the films at $350 \mathrm{~nm}$, at room temperature, $30{ }^{\circ} \mathrm{C}, 50{ }^{\circ} \mathrm{C}$ and $70{ }^{\circ} \mathrm{C}$ annealing temperature. It was observed that the reflectance values of all films remained almost constant at wavelengths after $500 \mathrm{~nm}$. Absorption band edge energies were found to vary from $3.06 \mathrm{eV}$ to $3.19 \mathrm{eV}$ at varying annealing temperatures. The highest refractive index at $440 \mathrm{~nm}$ is 3.46, which was obtained from the annealed film at $30^{\circ} \mathrm{C}$. The smallest refractive index value was obtained as 2.45 and obtained from annealed film at $120^{\circ} \mathrm{C}$. In the visible and near infrared spectrum, it was seen that the film tends to decrease with increasing annealed temperature, with an increasing tendency to absorption. In summary, by changing the annealing temperatures, the optical properties of the film were controlled and it was observed from experimental results that annealing at different temperatures had an important role on the optical properties of the film.

\section{REFERENCES}

Cheah LB, Rozana AMO, Poopalan P, 2020. Ga2O3 thin films by sol-gel method its optical properties. AIP Conference Proceedings, 2203: 020028. 
Chen D, Wang Z, Wang D, Wu YC, Lo CC, Lien A, Cao Y, Su SJ, 2015. Efficient exciplex organic light-emitting diodes with a bipolar acceptor. Organic Electronics, 25: 79-84.

Guo R, Zhang S, Yue S, Yan P, Wu Y, Qu D, Zhao Y, 2016. High efficiency and simplified white organic lightemitting diode based on a single-host emission layer. Synthetic Metals, 220: 329-333

Guo X, Yuan P, Qiao X, Yang D, Dai Y, Sun O, Qin A, Tang B, Ma D 2020. Mechanistic Study on High Efficiency Deep Blue AIE-Based Organic Light-Emitting Diodes by Magneto-Electroluminescence. Advanced Functional Materials, 30: 1908704.

Keshav B, Amit J, 2020. Fabricating gold nanorattles impregnated chitosan film for catalytic application. Materials Science for Energy Technologies, 3: 167-173.

Kim M, Lim C, Jeong D, Nam HS, Kim J, Lee J, 2016. Design of a MoOx/Au/MoOx transparent electrode for high-performance OLEDs. Organic Electronics, 36: 61-67.

Koh T, Cho W, Yun HC, Yoo S, 2012. ITO-free down-conversion white organic light-emitting diodes with structured color conversion layers for enhanced optical efficiency and color rendering. Organic Electronics, 13: 3145-3153.

Liang X, Wang K, Zhang LR, Guo K, Lu X, Wang K, Miao H, Xu H, Wang Z, 2017. Tetra-carbazole substituted spiro[fluorene-9,9'-xanthene]-based hole-transporting materials with high thermal stability and mobility for efficient OLEDs. Dyes and Pigments, 139: 764-771.

Lee Y, 1996. A Compact and Transmissive Device for Dispersion-Compensation of Ultra-short Optical Pulses. OPT REV, 3: 303-305.

Liu J, Li M, Lu Z, Huang Y, Pu X, Zhou L, 2020. Color tuning of iridium(III) complexes containing 2phenylbenzothiazole-based cyclometalated ligands for application in highly efficient organic light-emitting diodes. Dyes and Pigments, 175: 108145.Mullemwar S.Y, Zade GD, Kalyani NT, Dhoble SJ, 2016. Blue light emitting P-Hydroxy DPQ phosphor for OLEDs. Optik - International Journal for Light and Electron Optics, 127: 10546-10553.

Skuodis E, Tomkeviciene A, Reghu R, Peciulyte L, Ivaniuk K, Volyniuk D, Bezvikonnyi O, Bagdziunas G, Gudeika D, Grazulevicius JV, 2017. OLEDs based on the emission of interface and bulk exciplexes formed by cyano-substituted carbazole derivative. Dyes and Pigments, 139: 795-807.

Tsai YS, Hong LA, Juang FS, Chen CY, 2014. Blue and white phosphorescent organic light emitting diode performance improvement by confining electrons and holes inside double emitting layers. Journal of Luminescence, 153: 312-316.

Wan M, 1992. Absorption spectra of thin film of polyaniline. Journal of Polymer Science Part A: Polymer Chemistry, 30: 543-549.

Wu ZG, Zheng YX, Zhou L, Wang Y, Pan Y, 2017. Suppression of efficiency roll-off in highly efficient blue phosphorescent organic light-emitting devices using novel iridium phosphors with good electron mobility. Organic Electronics, 42: 141-145.

Yu T, Deng L, Xia P, Lu Y, Zhan N, Chen S, 2019. Ultrahigh-performance blue organic light-emitting diodes based on $\mathrm{SiO} 2$ coated $\mathrm{Ag}$ nanocubes and its working mechanism. Organic Electronics, 75: 105388.

Zhao B, Miao Y, Wang Z, Chen W, Wang K, Wang H, Hao Y, Xu B, Xu W, 2016. Highly efficient orange fluorescent OLEDs based on the energy transfer from bilayer interface exciplex. Organic Electronics, 37: $1-5$.

Zhao X, Zhou L, Jiang Y, Cui R, Li Y, Zhang H, 2016. Efficient organic blue fluorescent light-emitting devices with improved carriers' balance on emitter molecules by constructing supplementary light-emitting layer. Dyes and Pigments, 130: 148-153.

Zhou L, Jiang Y, Cui R, Li Y, Zhao X, Deng R, Zhang H, 2016. Efficient red organic electroluminescent devices based on trivalent europium complex obtained by designing the device structure with stepwise energy levels. Journal of Luminescence, 170: 692-696. 